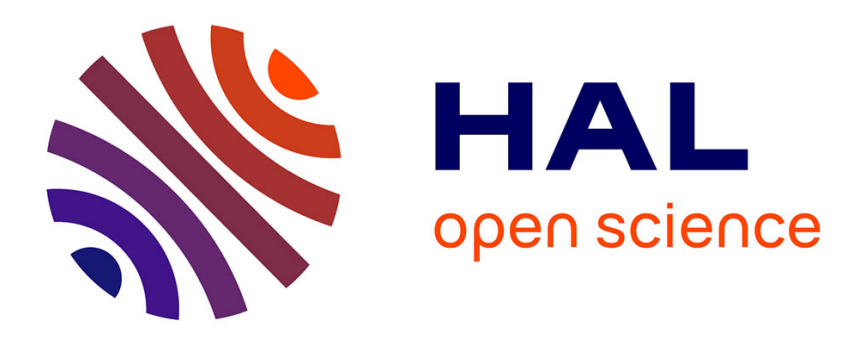

\title{
Parcel model simulations of aerosol? warm phase cloud microphysics interactions over the Amazon
}

\author{
A. A. Costa, S. Sherwood
}

\section{To cite this version:}

A. A. Costa, S. Sherwood. Parcel model simulations of aerosol? warm phase cloud microphysics interactions over the Amazon. Atmospheric Chemistry and Physics Discussions, 2005, 5 (1), pp.481508. hal-00303830

\author{
HAL Id: hal-00303830 \\ https://hal.science/hal-00303830
}

Submitted on 31 Jan 2005

HAL is a multi-disciplinary open access archive for the deposit and dissemination of scientific research documents, whether they are published or not. The documents may come from teaching and research institutions in France or abroad, or from public or private research centers.
L'archive ouverte pluridisciplinaire HAL, est destinée au dépôt et à la diffusion de documents scientifiques de niveau recherche, publiés ou non, émanant des établissements d'enseignement et de recherche français ou étrangers, des laboratoires publics ou privés. 


\section{Parcel model simulations of aerosol - warm phase cloud microphysics interactions over the Amazon}

\section{A. A. Costa ${ }^{1,2}$ and S. Sherwood ${ }^{1}$}

${ }^{1}$ Department of Geology and Geophysics, Yale University, New Haven, CT, USA

${ }^{2}$ Fundação Cearense de Meteorologia e Recursos Hídricos, Fortaleza, Brazil

Received: 19 October 2004 - Accepted: 9 December 2004 - Published: 31 January 2005

Correspondence to: A. A. Costa (alexandre.costa@yale.edu)

(C) 2005 Author(s). This work is licensed under a Creative Commons License.
$5,481-508,2005$

Parcel model simulations of aerosol

A. A. Costa and

S. Sherwood

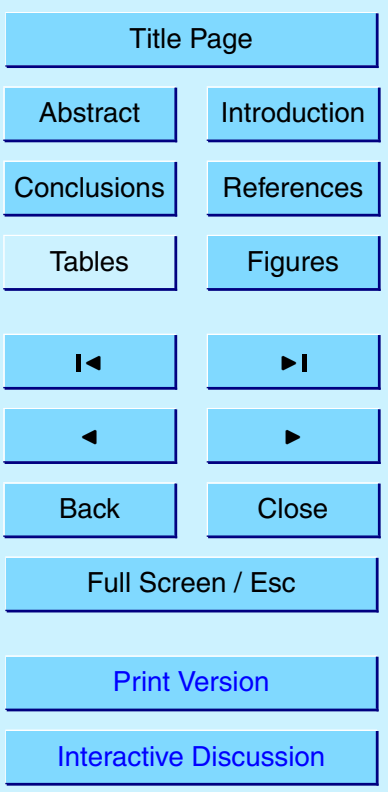




\section{Abstract}

Recent observational studies have shown that biomass burning aerosol can modify the microstructure of convective clouds in tropical regions such as Indonesia and the Amazon. In such regions warm rain development is evidently suppressed during the burning 5 season relative to the wet season, as numerous condensation nuclei produce more numerous but smaller cloud droplets. It is not clear, however, whether rain formation is affected only by CCN or whether other factors such as giant $\mathrm{CCN}$, updraft speeds, and atmospheric moisture also play important roles in the observed differences. These issues are addressed here using a simple parcel model to explain data collected during LBA-SMOCC-EMfiN! field campaign. The results suggest that polluted clouds in particular tend to be sensitive to each of these factors. When droplet concentrations exceed 500-1000 per cc, giant CCN (GCCN) become important by generating droplets that may eventually grow to precipitation size, though in cleaner environments warm rain occurs readily regardless of GCCN. Variations in the vertical velocity and in the low-level moisture are also shown to affect polluted clouds, and should be taken into account in interpreting microphysical differences observed among continental clouds.

\section{Introduction}

Atmospheric aerosols are a large source of uncertainty in explaining past climate change (e.g., Forest et al., 2002), and have become the subject of intense study. Changes in the aerosol concentrations and composition may lead to global modifications in cloud optical properties and precipitation formation processes (Ramanathan et al., 2001; Kaufman et al., 2002).

Over tropical regions, such as the Amazon, biomass burning is a major source of aerosols that serve as cloud condensation nuclei (CCN) (Kaufman et al., 1998; Artaxo et al., 1998, 2002). Changes in the cloud microphysics in association with smoke aerosols have been demonstrated in modeling studies (Roberts et al., 2003), satel-
ACPD

$5,481-508,2005$

Parcel model simulations of aerosol

A. A. Costa and

S. Sherwood

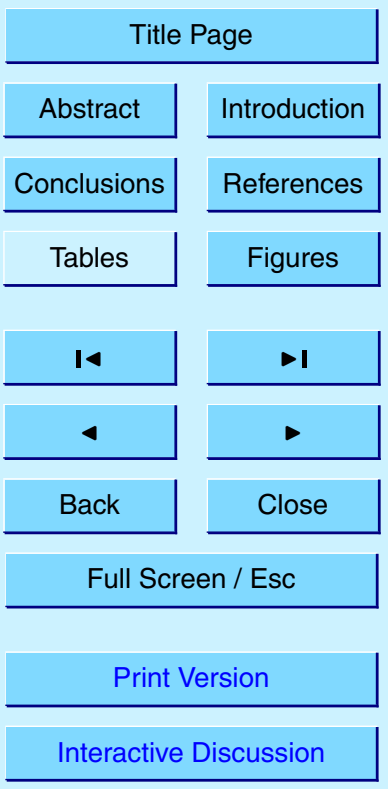


lite retrievals (e.g. Sherwood, 2002), and in-situ measurements (Andreae et al., 2004; Costa et al., 2004 ${ }^{1}$, hereafter A04 and C04, respectively). In particular, C04 provides a comprehensive analysis of field data from the Amazon region showing significant suppression of warm rain processes, in agreement with previous satellite and radar 5 studies (Rosenfeld, 1999).

Nevertheless, there are still many questions regarding the formation of precipitation in the Amazon clouds that cannot be answered from the in-situ data alone:

- What is the role of the giant cloud condensation nuclei (GCCN) found in the different environments? Previous modeling studies (e.g. Yin et al., 2000) suggest that in continental/polluted air masses, GCCN act as embryos for collector-size particles and might be able to trigger precipitation formation even in liquid-phase clouds with relatively high droplet concentrations. In contrast, clouds in clean environments would be insensitive to the presence or absence of GCCN, as numerous droplets formed on common $\mathrm{CCN}$ are able to evolve to precipitation-size hydrometeors.

- How do different updraft velocities influence precipitation development? It is well known that in the same environment, a population of clouds may exhibit a large variability in the strength of their updrafts. The vertical velocity is a critical parameter in the development of convective clouds, as it influences supersaturation, and hence the total amount of droplets that are nucleated from CCN. In addition strong updrafts are able to maintain precipitation-size particles within the cloud for longer periods, allowing enhanced collision-coalescence.

- How might changes in the environment influence microphysical development? For instance, during the transition from the dry to wet seasons over the Amazon,

${ }^{1}$ Costa, A. A., Rosenfeld, D., Andreae, M. O., da Silva Dias, M. A. F., Artaxo, P., Leal Jr., J. B. V., Pinheiro, F. G. M., da Silva, E. M., dos Santos, A. C. S., Freud, E., Frank, G. P., Almeida, G. P., and Silvério, A. C.: LBA-SMOCC-EMFIN!: Observations of interactions between aerosols and cloud microphysics over the Amazon, Earth Interactions, submitted, 2004.

ACPD

$5,481-508,2005$
Parcel model simulations of aerosol

A. A. Costa and

S. Sherwood

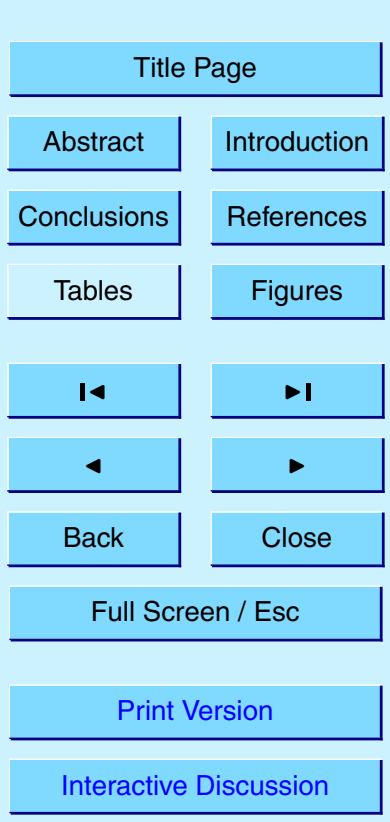


the moisture content available for convection increases, allowing clouds to have bases in lower altitudes. Does increased low-level water vapor mixing ratio affect the warm rain height (as defined in C04) as well?

Because the influence of many of those factors cannot be properly quantified from 5 ing that comprises the use of models with different levels of complexity, from very simple parcel models (e.g., Nenes et al., 2001, 2002) to complex cloud models (e.g., Yin et al., 2000, 2002) to even global models with (Grabowski, 2003) or without (Rotstayn and Lohmann, 2002; Chuang et al., 2002) an explicit cloud-resolving representation of convective clouds. Although such highly complex models probably account better for the existence of multiple processes that interact with each other, in order to better understand the role of a given factor (such as the ones listed above) to the precipitation formation, the use of simple models, such as parcel models, is sometimes preferable. For instance, Roberts et al. (2003) used a parcel model to simulate the early 15 development of cumulus clouds and showed that significant enhanced cloud droplet concentrations could rise from the increased population of aerosols during the burning season over the Amazon. Also using a parcel model with detailed microphysics, Segal et al. (2003) investigated the influence of thermodynamic parameters in the droplet spectrum and found that the surface humidity plays a significant role in shaping the 20 droplet size distribution.

In this paper, we use a parcel model to simulate the development of warm rain in different aerosol regimes, from very clean to extremely polluted, as well as to explore sensitivities regarding the presence of giant $\mathrm{CCN}$, the strength of the updraft velocities, and the availability of moisture at the sub-cloud layer. The outline of the paper is as follows: Sect. 2 describes the parcel model, Sects. 3 to 6 show results from different simulations, in which we explore the sensitivity regarding a number of parameters (total CCN concentration, presence of GCCN, vertical velocity and moisture), and Sect. 7 presents a summary and proposes future research.
ACPD

5, 481-508, 2005

Parcel model simulations of aerosol

A. A. Costa and

S. Sherwood

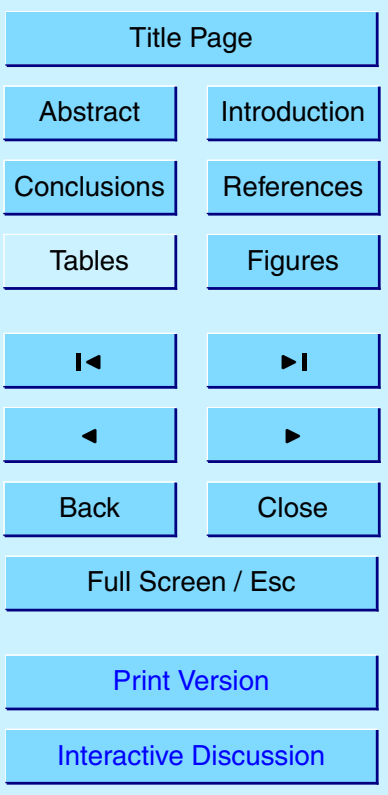




\section{Numerical model}

The numerical model is a parcel version of Costa et al.'s (2000) two-dimensional model, with explicit microphysics.

All major microphysical processes associated with the liquid phase are represented:

5 nucleation, condensation, evaporation, collision-coalescence, collisional and spontaneous breakup.

The model was set to allow up to 167 categories of aerosol particles, according to the specific needs of representing CCN of different sizes (including giant and/or ultragiant particles). The CCN dry radius ranges from approximately 0.006 to $7.59 \mu \mathrm{m}$, 10 corresponding to critical supersaturations of $3.0 \%$ (smallest nuclei) to approximately zero (largest nuclei).

Liquid-phase hydrometeors are divided into a set of 100 discrete bins, according to their radius, which varies exponentially from $1 \mu \mathrm{m}$ to $5 \mathrm{~mm}$. Kogan's (1991) scheme was used to redistribute mass among the discrete bins.

15 Probabilities of collision, followed by coalescence or breakup are calculated according to Low and List (1982a, b). Distribution-functions of fragments from filament, sheet and disk collisional breakup are calculated according to Low and List (1982b). As large raindrops are unstable, spontaneous breakup is included, following experimental data from Kamra et al. (1991).

20 The model is initialized with a cloud-free parcel at a specified temperature, pressure and humidity. The parcel is then forced to ascend at a specified vertical velocity. As the parcel rises, pressure is reduced according to a hydrostatic assumption and its temperature changes due to adiabatic expansion and diabatic release of latent heat due to condensation. Initial conditions correspond to field observations from the LBA-

SMOCC-EMfiN! Campaign (C04) and encompass different kinds of environment, from the oceanic/coastal type, at northern Northeast Brazil, in which higher dew-point temperatures provide a low lifting condensation level, to the warmer and dryer conditions over central Brazil and southern Amazon, in which cloud bases were predicted and

\section{ACPD}

$5,481-508,2005$

Parcel model simulations of aerosol

A. A. Costa and

S. Sherwood

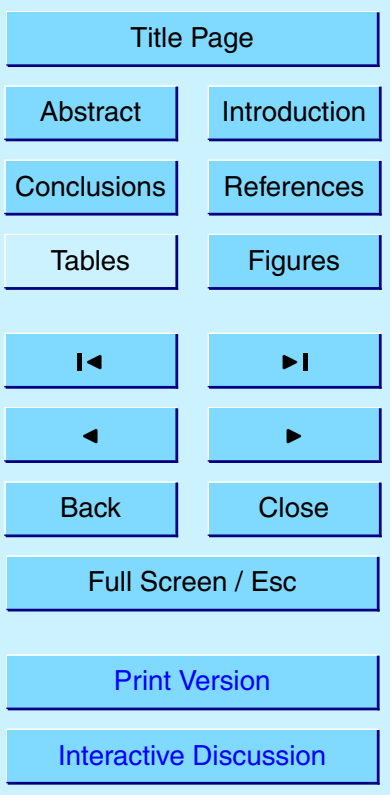


observed at a much higher altitude (see, for instance, C04's Fig. 8). Figure 1 shows the range of temperature and dew-point temperatures used to initiate the model. The surface conditions corresponding to the LBA-SMOCC-EMfiN! research flights are represented by small symbols (diamonds, squares, and triangles). The mean values of 5 temperature and dew-point temperature for the different cloud microphysics regimes (smoky, transitional, green ocean and blue ocean) are depicted as big symbols in the same diagram.

In order to simulate cloud development, a size-distribution of CCN has to be specified. In most of the simulations, an idealized distribution containing both large aerosols 10 ("common" CCN), giant and ultragiant CCN (UCCN) was used. That "control" distribution was then modified, reducing the concentrations of GCCN and/or UCCN or entirely removing GCCN and/or UCCN. Such distribution-functions are depicted in Fig. 2.

In order to simulate different aerosol concentrations, such distributions were simply multiplied by a factor, which allowed total CCN concentrations to range from $60 \mathrm{~cm}^{-3}$ to $1560000 \mathrm{~cm}^{-3}$ (at a $3.0 \%$ supersaturation). Such extreme values are meant to represent exceptionally clean environments, such as deep oceanic air masses (lowest concentration) and heavily polluted pyrocumulus formed over forest fires (highest concentration).

\section{Control set of simulations}

Many observational and modeling studies indicate that air masses containing many 20

\section{row spectra and virtually no precipitation development at the warm phase. For instance,}

aerosol particles tend to produce clouds with high droplet number concentrations, narA04 and $\mathrm{C} 04$ have shown that the altitude required for warm rain to develop in tropical convective clouds increases with increasing CCN concentration. This altitude is very important, as it controls the vertical profile of convective heating and the amount of
ACPD

$5,481-508,2005$

\section{Parcel model simulations of aerosol}

A. A. Costa and

S. Sherwood

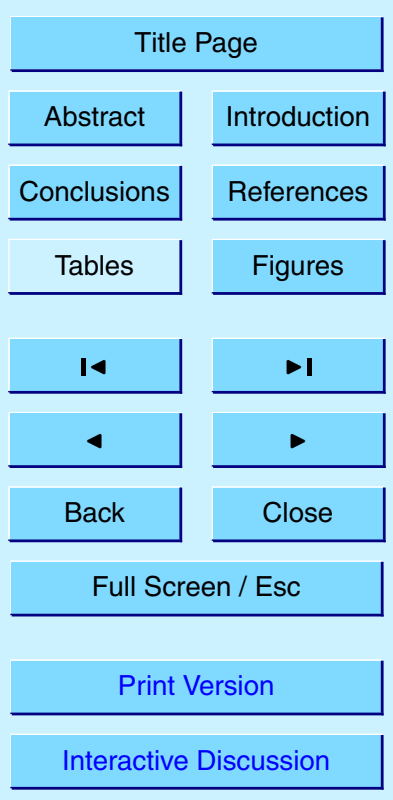

Here, we evaluate the influence of the total number concentration of $\mathrm{CCN}$ on the development of warm rain, using the parcel model described in the previous section. 
We first perform a control run initialized using the relatively dry conditions found during late September 2002 over the polluted, Southeastern, Amazon. We prescribe a vertical velocity of $3 \mathrm{~m} / \mathrm{s}$ and a control aerosol distribution that includes GCCN and UCCN.

Figure 3 shows the simulated warm rain height (assumed as the minimum altitude 5 at which the modal liquid water diameter reaches a value of $D_{R}=24 \mu \mathrm{m}$, which permits a direct comparison with results from A04 and C04), as well as observed values (from C04) for a wide range of droplet concentrations. Both the model and observations show a general tendency toward increased warm rain height $(\zeta)$ with increased cloud droplet concentration.

10 The predicted warm rain height exhibits an obvious change in behavior when the cloud droplet concentration exceeds $\sim 700 \mathrm{~cm}^{-3}$. For concentrations less than this value (i.e., for cleaner environments), the warm rain height increases nonlinearly with CCN concentration. That part of the plot is well explained using very simple arguments on how the available water vapor condenses on a given number of aerosol particles. 15 The adiabatic liquid water content is $q_{l}=\frac{\pi}{6} \rho_{w} \bar{D}^{3} N$, where $\rho_{w}, N$, and $\bar{D}$ represent the density of liquid water, the total hydrometeor number concentration and the massaveraged diameter

$\bar{D}=\left(\frac{1}{N} \int_{0}^{\infty} f(D) D^{3} d D\right)^{1 / 3}$

$(f(D)$ is the number distribution-function), respectively. In the absence of coalescence or

sedimentation processes, the liquid water content will remain adiabatic and the droplet size distribution will be narrowly distributed about the modal diameter $D_{R}$. The warm rain height would occur at $\zeta=F^{-1}\left(\frac{\pi}{6} \rho_{w} D_{R}^{3} N\right)$, where we assume that $\bar{D}$ equals the threshold modal diameter $\left(D_{R}\right)$. This adiabatic, monomodal estimate is represented by the grey line in Fig. 3. It is obvious that such an approximation accounts very well for 25 the behavior of the parcel model in the clean regime.

However, for droplet concentrations bigger than $\sim 800 \mathrm{~cm}^{-3}$, the simulated warm rain 487
ACPD

$5,481-508,2005$

Parcel model simulations of aerosol

A. A. Costa and

S. Sherwood

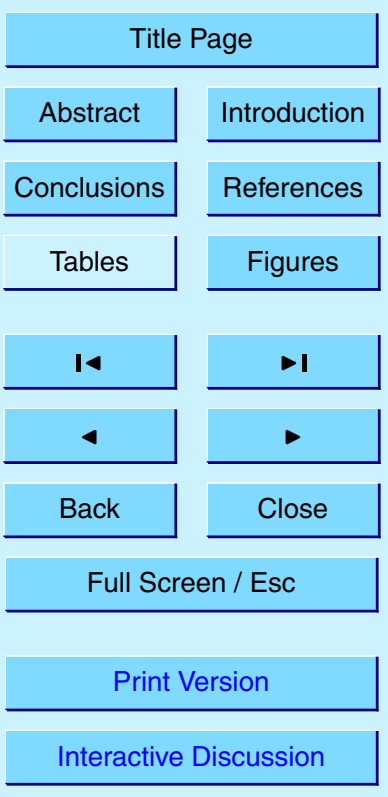

EGU 
height increases at a significantly smaller rate than it does for lower concentrations. This change in behavior keeps the model somewhat close to observations, while the adiabatic/monomodal calculation obviously departs from reality. The change in behavior arises from the physics of the coalescence processes. Collision and coalescence 5 efficiencies in the model depend on the sizes of both particles involved. Collisions by droplets of similar size are unlikely to coalesce, until their radii approach $25 \mathrm{mi}-$ crons where coalescence quickly becomes efficient. This is the reason for the modaldiameter warm-rain threshold commonly assumed. Collisions by particles of different size are more likely, and can occur even when the larger droplet is too small to coa10 lesce with a droplet of its own size. Thus, colloidal instability may be attained either through sufficient broadening, or through overall enlargement, of the droplet sizes.

In a clean environment, the relatively small population of droplets undergoes sufficiently rapid growth via condensation so that nearly all droplets attain the 24-micron threshold before sufficient broadening has occurred to allow coalescence at smaller

modal diameters. Thus, rapid onset of precipitation is predicted at the height indicated by our adiabatic/monomodal calculation. Above a critical CCN concentration, however, sufficient broadening is simulated prior to the attainment of the size threshold to allow "early" coalescence. This broadening is greatly facilitated by even miniscule numbers of GCCN/UCCN. The height at which this occurs increases little with further increases in $\mathrm{CCN}$, but is sensitive to GCCN/UCCN.

This explanation is illustrated by Fig. 4, which depicts mass distribution-functions for two extreme cases (clean, panel a, versus polluted, panel b). In the clean case, during the condensational growth stage, the mass acquired by the smaller particles is very significant (since there are only few of them to compete for the water vapor) and the mode in the mass distribution-function progresses rapidly, as the small particles tend to catch up with the originally large ones. In contrast, in the polluted case, the raindropsize particles that appear in upper levels in the simulated cloud (still with fairly low total mass) are able to gain mass via collection of some of the smaller particles (at least the ones that are not so small, so they don't follow the air flow around the collector). The
ACPD

$5,481-508,2005$

Parcel model simulations of aerosol

A. A. Costa and

S. Sherwood

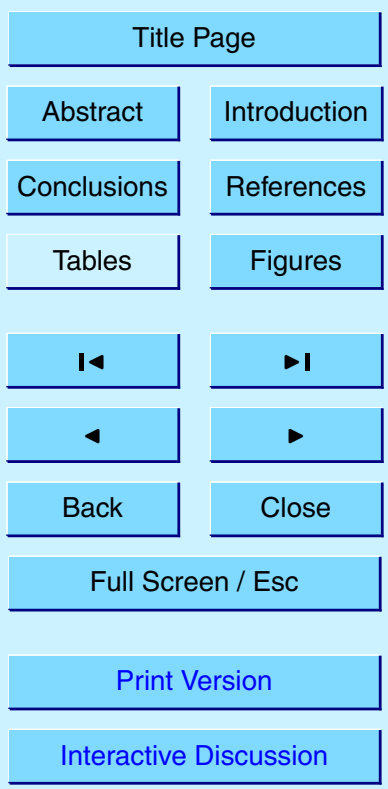


growth of the largest particles via collection is faster than the condensational growth, because of the large number of droplets competing for the water vapor. Because of the presence of the larger $\mathrm{CCN}$ that produce those large hydrometeors, the adiabatic assumption fails. In the polluted case, therefore, it is probable that the largest particles

5 (GCCN and UCCN) tend to be very important as precipitation embryos, as suggested by the hydrometeor spectra shown in Fig. 4 and tested later in this paper.

It is clear, however, that the parcel model is so far not able to fully represent the observed features shown in Fig. 3. The discrepancies between model results and observations may be attributed to a number of factors. For the clouds formed over the

10 Atlantic Ocean, off the Brazilian coast, the abundance of water vapor allowed clouds to form at much lower clouds bases. Also, the vertical velocity we used is certainly overestimated, as flight logs from the LBA-SMOCC-EMfiN! campaign suggest that the updrafts were much weaker in that case. This surely contributes to an overestimated model warm rain height, as compared to the observations. In contrast, the simulated warm rain height appears to be underestimated in the polluted case, which might be caused by a combination of two factors: the underestimation of the core updraft vertical velocities and the constraint that prevents GCCN and UCCN leaving the parcel via dry deposition. All these factors are going to be explored in the following sections, in order to assess the model sensitivity associated with them. In addition, it is possible that droplet concentrations in the polluted regime are being underestimated due to coincidence errors (C04).

\section{Role of GCCN and UCCN}

Under certain conditions, GCCN and UCCN may be responsible for the formation of raindrop embryos, as pointed out by a number of authors (Johnson, 1982; Kuba and 25 Takeda, 1983). Those works, along with the one by Yin et al. (2000), show evidences that GCCN and UCCN are important in the warm rain development in air masses with higher aerosol concentrations, whereas, in clean air masses, their influence is rather

ACPD

$5,481-508,2005$

Parcel model simulations of aerosol

A. A. Costa and

S. Sherwood

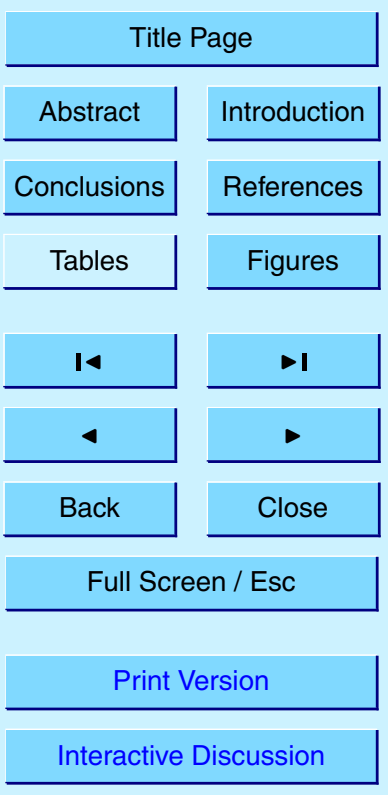

EGU 
small.

In the Amazon, the large temporal and spatial variability in the aerosol field may produce situations in which the presence of such aerosol particles is indeed important in the rain formation process. In fact, $\mathrm{C} 04$ have shown that in clean air masses (such as 5 the ones over the western Amazonia) precipitation-size particles appear as a result of spectral broadening, which possibly makes the presence of GCCN or UCCN of little consequence, whereas droplet size-distributions found in polluted environments are similar to the ones depicted in panel $4 \mathrm{~b}$, and often exhibit a second mode in mass, which may grow as the air parcel ascends inside a convective cloud. Their results sug10 gest that during the dry-to-wet season transition in Amazonia, this process of growth might account, at least in part, for the lowering of warm rain height.

Since LBA-SMOCC-EMfiN! observations were very limited regarding the presence and role of GCCN and UCCN, we investigated their role in the precipitation initiation process via modeling.

15 The parcel model was initialized with the relatively dry conditions found during late September 2002 over Southeastern Amazon ("smoky" period) and, as before, a prescribed vertical velocity of $3 \mathrm{~m} / \mathrm{s}$ was used. However, in the sensitivity experiments described in this section, the different CCN distributions in Fig. 2 were tested (control, no UCCN, reduced GCCN/UCCN, and no GCCN/UCCN).

Results for those numerical experiments are depicted in Fig. 5. In agreement with previous studies, they suggest that GCCN and UCCN are irrelevant when droplet number concentration is below $700-800 \mathrm{~cm}^{-3}$. Above this, the role of the GCCN and UCCN in lowering $\zeta$ becomes significant. For polluted environments having concentrations on the order of $2000 \mathrm{~cm}^{-3}$, the difference in $\zeta$ in the control simulation (i.e., with GCCN and UCCN) and in the no GCCN simulation is close to $2 \mathrm{~km}$ for the given initial conditions and prescribed vertical velocity. The model results suggest that the tiny population of ultra-giant particles is important too, as their absence in the no-UCCN simulation leads to an additional $1-\mathrm{km}$ increase in $\zeta$. Results from the sensitivity experiment with reduced GCCN and UCCN suggest that their presence, even in very small concentra-
ACPD

$5,481-508,2005$

Parcel model simulations of aerosol

A. A. Costa and

S. Sherwood

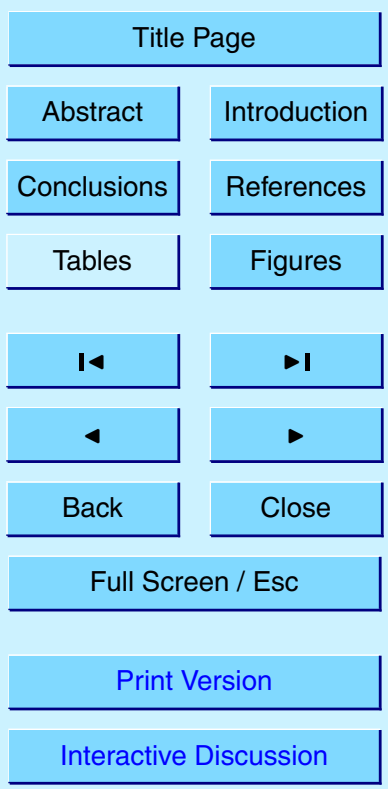

EGU 
tions (relatively to the total $\mathrm{CCN}$ concentration), lowers the altitude required for warm rain formation in comparison to the simulation with no GCCN/UCCN.

The idea that large droplets nucleated over GCCN may serve as precipitation is not new (see, for instance, Johnson, 1982), but it is still debatable whether or not the pres5 ence of giant smoke or ash particles in the polluted Amazon could at least mitigate warm rain suppression associated with the very large CCN concentrations. C04's results suggest that the presence of GCCN may be one of the factors that account for the changes in the cloud properties (with the occurrence of warm rain becoming more probable during the transition to the wet season).

10 Indeed, the model results suggest that the droplet spectra in a polluted environment evolve in a different way when GCCN are not present. Figure 6 shows distribution functions (as in Fig. 4) for the two extreme cases, but for no GCCN simulations. The no GCCN droplet spectra in a clean environment (Fig. 6a) are very similar to their counterparts in the control simulation (Fig. 4a). However, in the polluted, no GCCN simulation, there are no signs of precipitation-size particles (Fig. 6b), in contrast with the control simulation, in which the presence of GCCN allowed a second mode to appear, in accordance to C04 observations (Fig. 4b). Those simulations suggest that the most polluted environments are the most sensitive to the presence of giant and ultra-giant particles.

\section{Microphysical variability associated with vertical velocity}

Vertical velocity within updrafts varies widely within and among cloud systems, in ways that are difficult to measure and not well understood theoretically. In order to assess the microphysical sensitivity to the vertical velocity $(w)$, several sets of numerical experiments were performed, in which we prescribed $w=2,3,4$, and $6 \mathrm{~m} / \mathrm{s}$, for the same distribution of aerosols.

The vertical velocity affects microphysical development in two ways. First, $w$ de-

ACPD

$5,481-508,2005$

Parcel model simulations of aerosol

A. A. Costa and

S. Sherwood

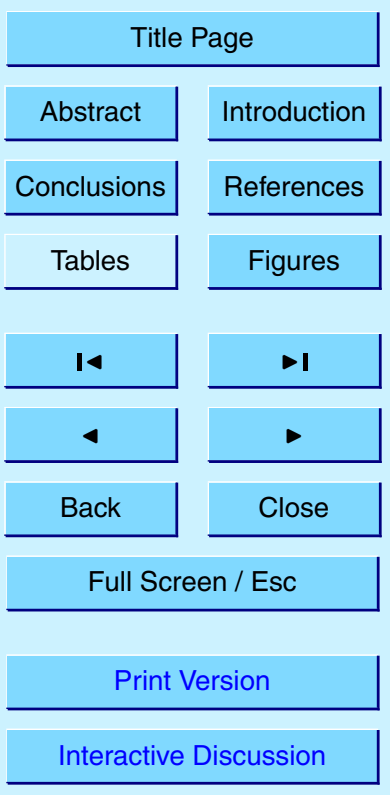

EGU 
termines the rate at which adiabatic expansion of a cloud parcel produces supersaturation, which in turn controls the number of CCN that are activated.. This well-known effect causes, in our model, roughly a doubling of the maximum droplet number concentration $N$, going from $w=2$ to $8 \mathrm{~m} / \mathrm{s}$ and holding CCN fixed. Though this affects $N$, it 5 would not obviously alter the function $\zeta(N)$. Second, a more rapid ascent of the cloud parcel leaves less time for coalescence processes to occur. This should reduce $\zeta$ for a given $N$, but only when $N>700$ or so and we are in the polluted model regime.

Results shown in Fig. 7 confirm that the modeled warm rain height is insensitive to the vertical velocity for low droplet concentrations $N$, regardless of why $N$ is low. This 10 is not the case for larger $N$, where $\zeta$ increases with $N$. Given a fixed period of time, the smaller distance traveled by the cloud parcel with a small vertical velocity allows a larger number of collection events to occur, and therefore large droplets originated over the largest CCN are able to reach precipitation-size at lower altitudes, as opposed to the case of strong updrafts.

\section{6. The importance of the low-level humidity}

The most obvious impact of the initial temperature and water vapor mixing ratio in the parcel is in controlling the cloud base height, which should depend on dewpoint depression. During the SMOCC-LBA-EMfiN! campaign, C04 showed that cloud bases were roughly at $500 \mathrm{~m}$ over the "blue ocean", whereas in the polluted and green ocean regimes, cloud bases were much higher (1500 $\mathrm{m}$ or more at times). During the transitional regime, the increased low-level dew points led to a reduction in the cloud base height to about $1200 \mathrm{~m}$. These heights were approximately reproduced by the model, in which adiabatic parcels first saturated at at $860 \mathrm{~m}$ (blue ocean) $1360 \mathrm{~m}$ (transition), $1630 \mathrm{~m}$ (polluted), and $1700 \mathrm{~m}$ (green ocean).

25 To explore the sensitivity to temperature and humidity, simulations were performed using the range of temperatures and dew points found during the LBA-SMOCC-EMfiN! campaign (see Fig. 1), keeping the control CCN distribution (i.e., with both GCCN and

\section{ACPD}

$5,481-508,2005$

Parcel model simulations of aerosol

A. A. Costa and

S. Sherwood

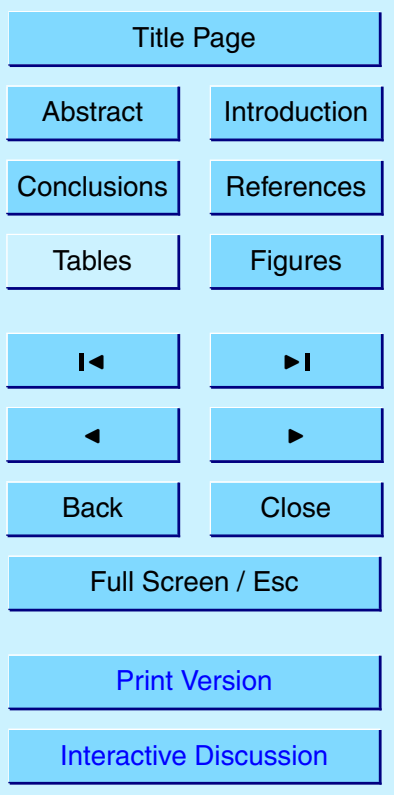


UCCN included) and a fixed vertical velocity of $3 \mathrm{~m} / \mathrm{s}$. The outcome is depicted in Fig. 8 , which again shows $\zeta(N)$ for the various initial parcel states.

An obvious feature in Fig. 8 is that the warm rain height is more sensitive to moisture than is the cloud base height, especially for higher droplet concentrations. For instance, 5 from the polluted to the transition cases, there was a reduction in the simulated cloud base height of $270 \mathrm{~m}$, whereas the warm rain heights differs by more than $500 \mathrm{~m}$ at a $2000 \mathrm{~cm}^{-3}$ droplet number concentration, with GCCN included. It is clear that this discrepancy increases with $N$. Also, it is larger when GCCN are not present (in the no GCCN simulations, it increases to about $700 \mathrm{~m}$ for a $2000 \mathrm{~cm}^{-3}$ droplet number 10 concentration).

The fact that subtle changes in the low-level humidity lead to modest variations in the cloud base heights, but more substantial changes in the warm rain height, is associated with the non-linearity of the Clausius-Clapeyron equation, and is illustrated in Fig. 9. The two lines in Fig. 9 represent the vertical profile of the saturation water vapor mixing

ratio for the polluted environment (red line) and the transition environment (orange line), as calculated from the parcel model in the control set of simulations. One should note that, as discussed previously and shown in Fig. 8, cloud base altitudes in those two environments differ by $270 \mathrm{~m}$. Above cloud base, in the simulated parcel, the excess of water substance turns into the liquid phase, which, in Fig. 9, is simply the distance between the saturation curve and the vertical line drawn at the cloud base. As the parcel ascends, warm rain development is expected to occur for a certain mixing ratio (this threshold MR is expected to be a function of the droplet concentration). In case of a $2000 \mathrm{~cm}^{-3}$ droplet concentration, the drier conditions found in the smoky Amazon environment gives us a warm rain height of $5310 \mathrm{~m}$. For the same threshold

MR (indicated by the horizontal solid lines with arrows), and assuming the same droplet concentration, the curved shape of the saturation mixing ratio profile gives a warm rain height of $4800 \mathrm{~m}$ in the slightly moister environment found during the transition. Because of the non-linearity in the vertical profile of the saturation mixing ration, the difference in the warm rain heights is almost twice as large as the difference in the

\section{ACPD}

5, 481-508, 2005

Parcel model simulations of aerosol

A. A. Costa and

S. Sherwood

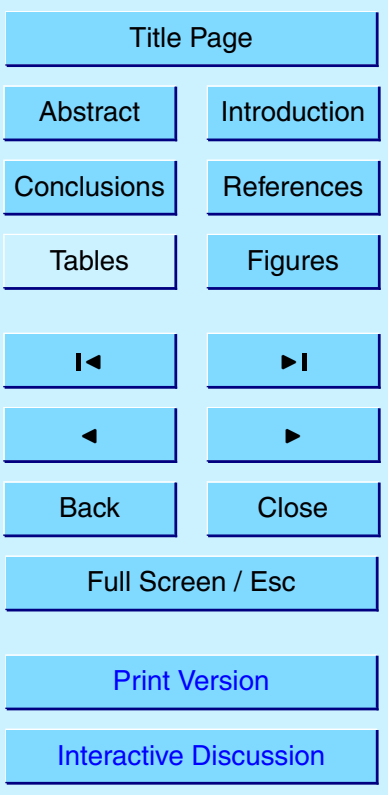




\section{Integrated assessment}

$5,481-508,2005$

Finally, we reconsider the ability of the model to simulate the LBA-SMOCC-EmfiN! observations with realistic combinations of the above factors for each case. This is difficult owing to the fact that vertical velocities $w$ were not directly observed, and GCCN observations are also highly uncertain. However, the results are encouraging. Figure 10 compares the simulated and observed warm rain heights, with and without GCCN. In each case, error bars show the range of results obtained for a proposed, likely range of $w$ based on estimates informed in LBA-SMOCC-EMfiN! flight reports, which show that convection was more intense over the Amazon than over the Brazilian coast. The model results are significantly more uncertain in the smoky and transitional regimes, because of the increased sensitivity to $w$.

The results show that, once variations in moisture, vertical velocity, and GCCN are taken into account, the model's ability to simulate the observed variations improves 15 significantly (compare with Fig. 3). The model does tend to overestimate the warm rain height, especially in the blue ocean regime. This is not unexpected, since "observed" warm rain heights are based on the detection of precipitation-sized hydrometeors, which must occur below the height where they first formed if they are already sedimenting (which was probably the case in the more maritime examples). We are unable to assess whether this fully explains the discrepancy, or whether other model or observational shortcomings are also important.

\section{Discussion}

In this paper, we addressed, using a simple parcel model of upward moving air in convection, several issues regarding the precipitation formation over the Amazon. In

\section{Parcel model simulations of aerosol}

A. A. Costa and

S. Sherwood

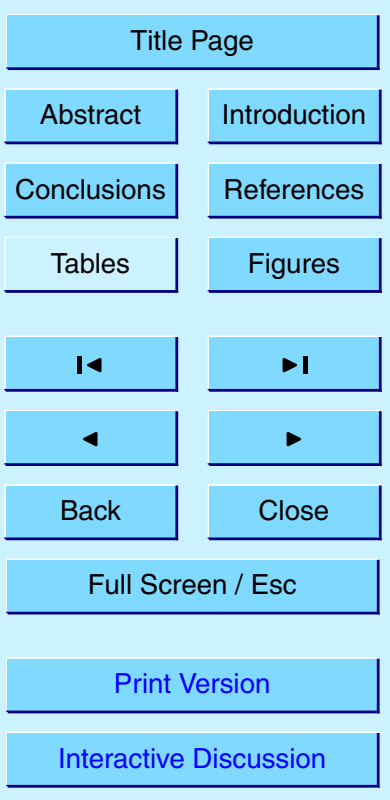


agreement with observational studies (particularly A04 and C04), we find that the large seasonal variations in the CCN concentrations over that region are able to produce significant differences in the cloud characteristics.

It is important to note, however, that the seasonal cycle in burning is accompanied 5 by a similar moisture cycle. We have argued that simple "Twomey effect" thinking (adiabatic water content distributed over variable droplet numbers) can only apply in clean environments. In polluted environments, our model results indicate that the height for warm precipitation is governed not by overall growth of mean particle size, as is the case in clean environments, but rather by the breadth in the droplet spectrum. In 10 the simulations, collection growth by large particles apparently dominates condensational growth in producing precipitation-size particles in polluted environment. As a consequence, the system becomes sensitive to the presence of giant and ultragiant $\mathrm{CCN}$, since they are responsible for nucleating the larger droplets that might act as collectors. This is not the case in cleaner environments (droplet concentrations below

$15700-800 \mathrm{~cm}^{-3}$ ), where GCCN and UCCN are irrelevant for the warm rain development as argued in earlier studies.

The simulations also indicate that polluted clouds are more sensitive to vertical velocity than clean clouds. In either type the vertical velocity should exert some control in the droplet concentration, as stronger updrafts allow a larger number of $\mathrm{CCN}$ to be activated. But in polluted clouds, we find that the warm rain height is further reduced when updrafts are weak, as more collection can occur within a given altitude range and the larger droplets nucleated over GCCN and UCCN reach precipitation-size at lower altitudes. Therefore, the vertical velocity in a polluted environment might play a double role, with the warm rain height being lowered (elevated) in weaker (stronger) updrafts, due both the activation of a smaller (larger) number of droplets and the increase (decrease) in the number of collision events between the larger hydrometeors nucleated over GCCN/UCCN and other droplets.

Finally, we showed that low-level moisture also appears important in changing the warm rain height, especially when droplet concentrations are large. Predicted warm

\section{ACPD}

$5,481-508,2005$

Parcel model simulations of aerosol

A. A. Costa and

S. Sherwood

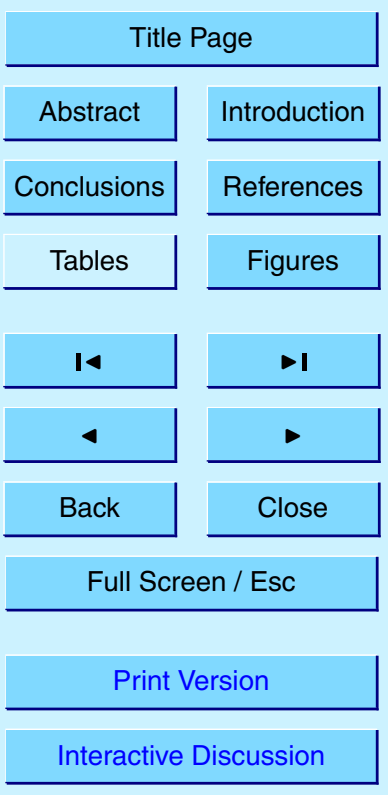


rain height varies with low-level moisture in the same sense as cloud base height, but with much more sensitivity, because the saturation mixing ratio is a highly nonlinear function of temperature (and consequently of height). In polluted environments, subtle variations in boundary layer water vapor mixing ratio might lead to significant 5 variations in the height of warm rain formation. Along with the reduction of the total CCN concentrations, this is possibly an important factor driving the changes in the production of precipitation from the dry to the wet season over the Amazon.

Acknowledgements. This work was funded by the NSF CAREER program.

\section{References}

Andreae, M. O., Rosenfeld, D., Artaxo, P., Costa, A. A., Frank, G. P., Longo, K. M., and SilvaDias, M. A. F.: Smoking Rain Clouds over the Amazon, Science, 303, 1337-1342, 2004.

Artaxo, P., Fernandes, E. P., Martins, J. V., Yamasoe, M. A., Hobbs, P. V., Maenhaut, W., Longo, K. M., and Castanho, A.: Large-scale aerosol source apportionment in Amazonia, J. Geophys. Res., 103, 31 837-31847, 1998.

15 Costa, A. A., Almeida, G. P., and Sampaio, A. J. C.: A bin-microphysics cloud model with high-order, positive-definite advection, Atmos. Res., 55, 225-255, 2000.

Forest, C. E., Stone, P. H., Sokolov, A. P., Allen, M. R., and Webster, M. D.: Quantifying uncertainties in climate system properties with the use of recent climate observations, Science, 295, 113-117, 2002.

Grabowski, W. W.: Impact of cloud microphysics on convective-radiative quasi equilibrium revealed by cloud-resolving convection parameterization, J. Climate, 16, 3463-3475, 2003.

Kamra, A. K., Bhalwankar, R. V., and Sathe, A. B.: spontaneous breakup of charged and uncharged water drops freely suspended in a wind-tunnel, J. Geophys. Res., 96, 1715917 168, 1991.

25 Kaufman, Y. J., Hobbs, P. V., Kirchoff, V. W. J. H., Artaxo, P., Remer, L. A., Holben, B. N., King, M. D., Ward, D. E., E. Prince, M., Longo, K. M., Mattos, L. F., Nobre, C. A., Spinhirne, J. D., Ji, Q., Thompson, A. M., Glason, J. F., Christopher, S. A., and Tsay, S. C.: Smoke, clouds and radiation - Brazil (SCAR-B) experiment, J. Geophys. Res., 103, 31 783-31 808, 1998.

ACPD

$5,481-508,2005$

Parcel model simulations of aerosol

A. A. Costa and

S. Sherwood

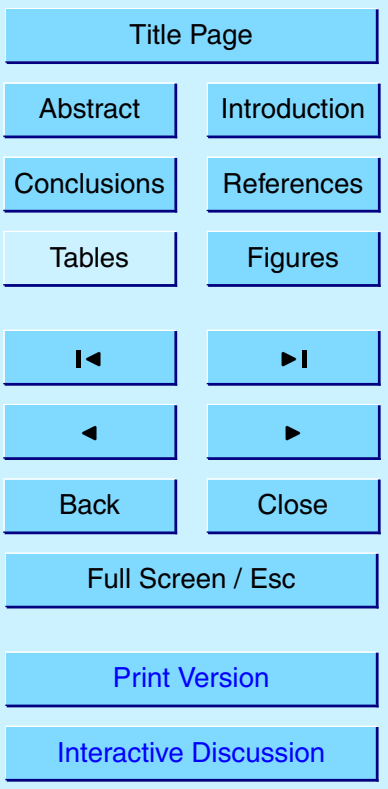


Kaufman, Y. J., Tanre, D., and Boucher, O.: A satellite view of aerosols in the climate system, Nature, 419, 215-223, 2002.

Kogan, Y. L.: The simulation of a convective cloud in a 3-d model with explicit microphysics, 1. Model description and sensitivity experiments, J. Atmos. Sci., 48, 1160-1189, 1991.

5 Low, T. B. and List, R.: Collision, coalescence and breakup of raindrops, 1. Experimentally established coalescence efficiencies and fragment size distributions in breakup, J. Atmos. Sci., 39, 1591-1606, 1982a.

Low, T. B. and List, R.: Collision, coalescence and breakup of raindrops, 2. Parameterization of fragment size distributions, J. Atmos. Sci., 39, 1591-1606, 1982b.

10 Nenes, A., Ghan, S., Abdul-Razzak, H., Chuang, P. Y., and Seinfeld, J. H.: Kinetic limitations on cloud droplet formation and impact on cloud albedo, Tellus B, 53, 133-149, 2001.

Nenes, A., Charlson, R. J., Facchini, M. C., Kulmala, M., Laaksonen, A., and Seinfeld, J. H.: Can chemical effects on cloud droplet number rival the first indirect effect?, Geophys. Res. Lett., 29 (17), art. no. 1848, doi:10.1029/2002GL015295, 2002.

Ramanathan, V., Crutzen, P. J., Kiehl, J. T., and Rosenfeld, D.: Atmosphere - Aerosols, climate, and the hydrological cycle, Science, 294, 2119-2124, 2001.

Rosenfeld, D.: TRMM observed first direct evidence of smoke from forest fires inhibiting rainfall, Geophys. Res. Lett., 26, 3105-3108, 1999.

Segal, Y., Pinsky, M., Khain, A., and Erlick, C.: Thermodynamic factors influencing bimodal spectrum formation in cumulus clouds, Atmos. Res., 66, 43-64, 2003.

Sherwood, S. C.: Aerosols and ice particle size in tropical cumulonimbus, J. Climate, 15, 10511063, 2002.

Yin, Y., Levin, Z., Reisin, T. G., and Tzivion, S.: The effects of giant cloud condensation nuclei on the development of precipitation in convective clouds - a numerical study, Atmos. Res., 53, 91-116, 2000.

Yin, Y., Wurzler, S., Levin, Z., and Reisin, T. G.: Interactions of mineral dust particles and clouds: Effects on precipitation and cloud optical properties, J. Geophys. Res., 107 (D23), art. no. 4724, doi:10.1029/2001JD001544, 2002.

Parcel model simulations of aerosol

A. A. Costa and

S. Sherwood

\section{Title Page}

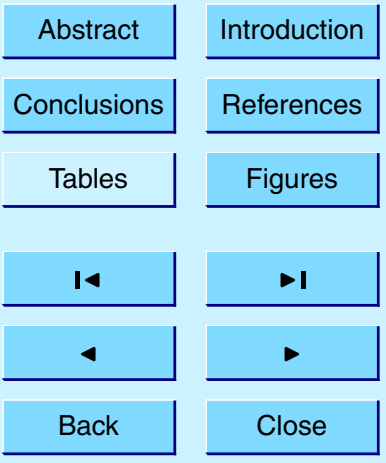

Full Screen / Esc

Print Version

Interactive Discussion 


\section{ACPD}

$5,481-508,2005$

Dry (20020923 to 20021004) versus Transition (20021008 to 20021014) versus Green Ocean (20021005) versus Blue Ocean (20021018)

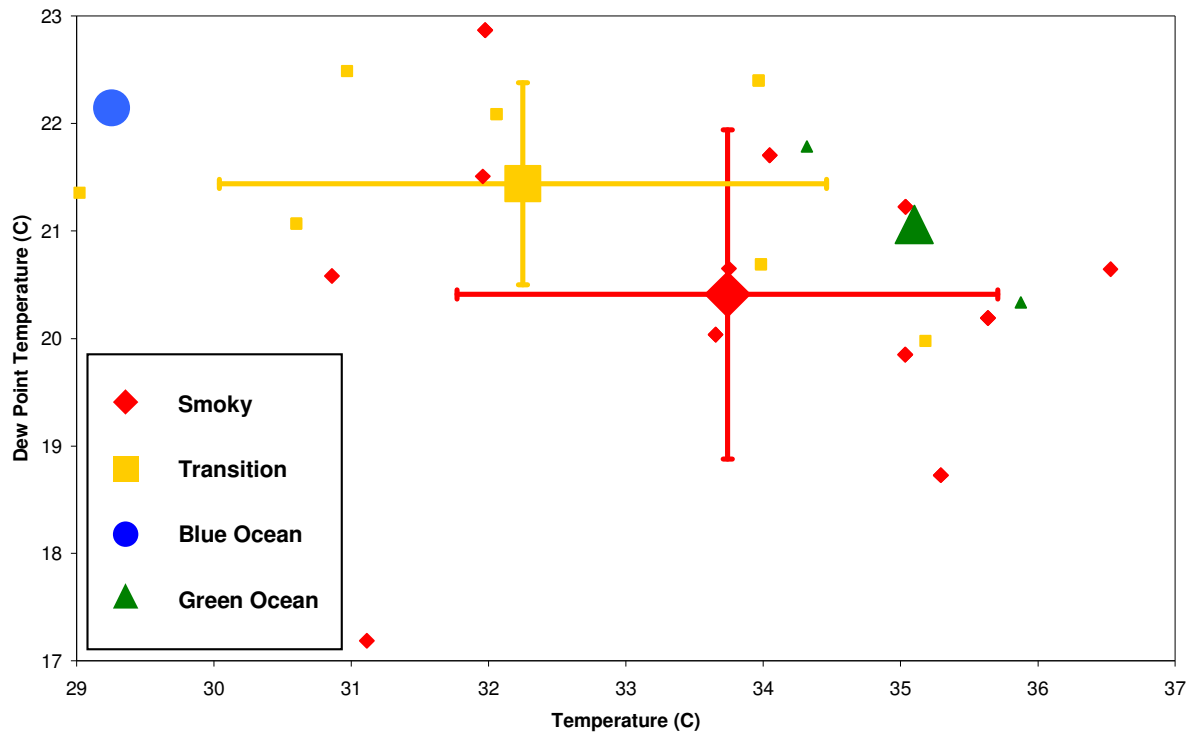

\section{Parcel model simulations of aerosol}

A. A. Costa and

S. Sherwood

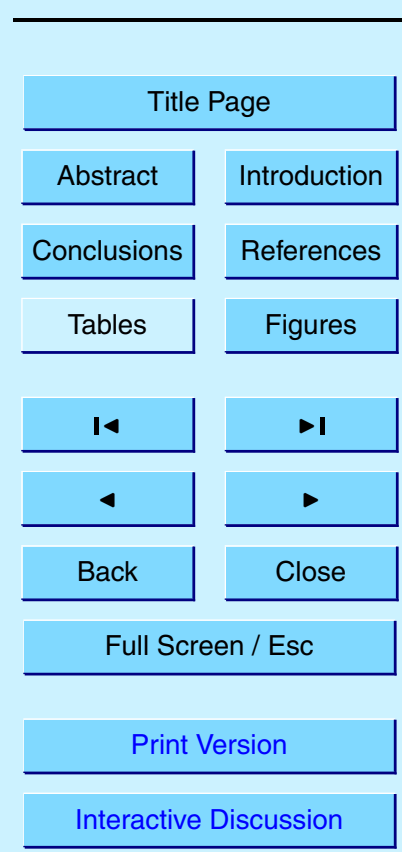

Fig. 1. Observations of temperature and dew-point temperatures from the LBA-SMOCC-EMfiN! campaign. Colors indicate different regimes: smoky (red), transition (orange), "green ocean" (green) and coastal/"blue ocean" (blue). Small symbols represent individual observations, and averages for the different regimes are indicated by large symbols. Error bars indicate standard deviations for the smoky and the transitional regimes. 


\section{ACPD}

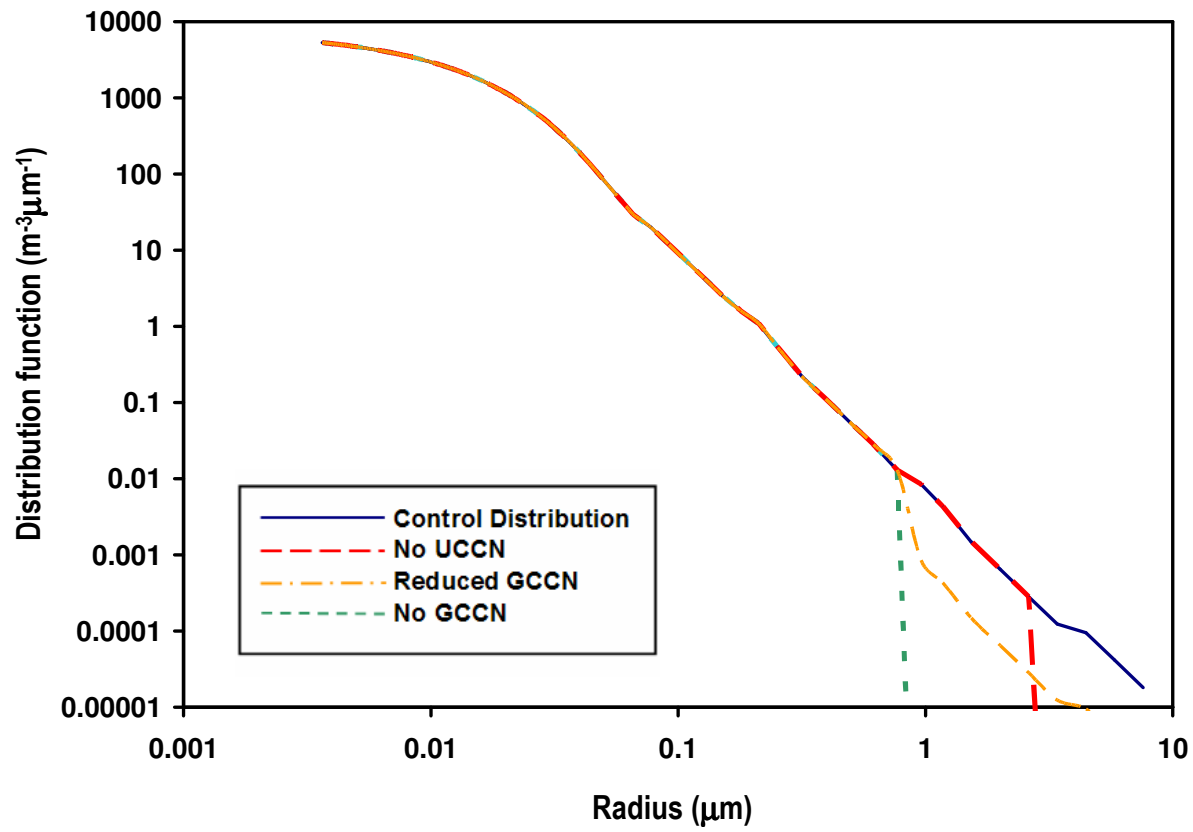

$5,481-508,2005$

Parcel model simulations of aerosol

A. A. Costa and

S. Sherwood

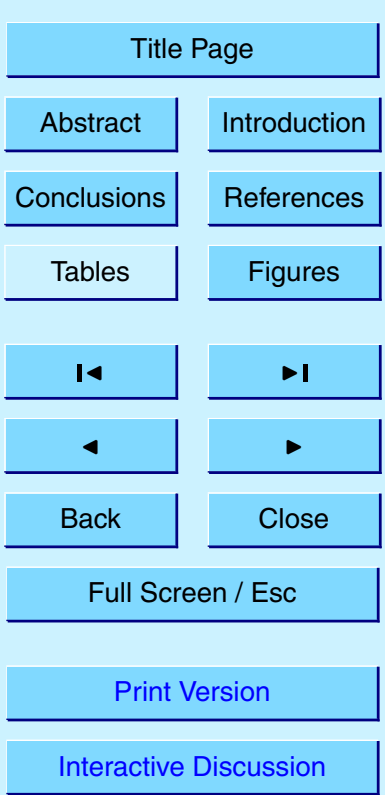

Fig. 2. Idealized $\mathrm{CCN}$ distributions. The control distribution contains common $\mathrm{CCN}$, giant and ultragiant CCN. Modified distributions are such that the concentration of GCCN/UCCN was reduced ("reduced GCCN") or the population of UCCN or GCCN was completely removed ("no UCCN", "no GCCN", respectively). In the actual simulations, this distribution-function is multiplied by a factor, in order to represent environments ranging from very clean to extremely polluted. 


\section{ACPD}

$5,481-508,2005$

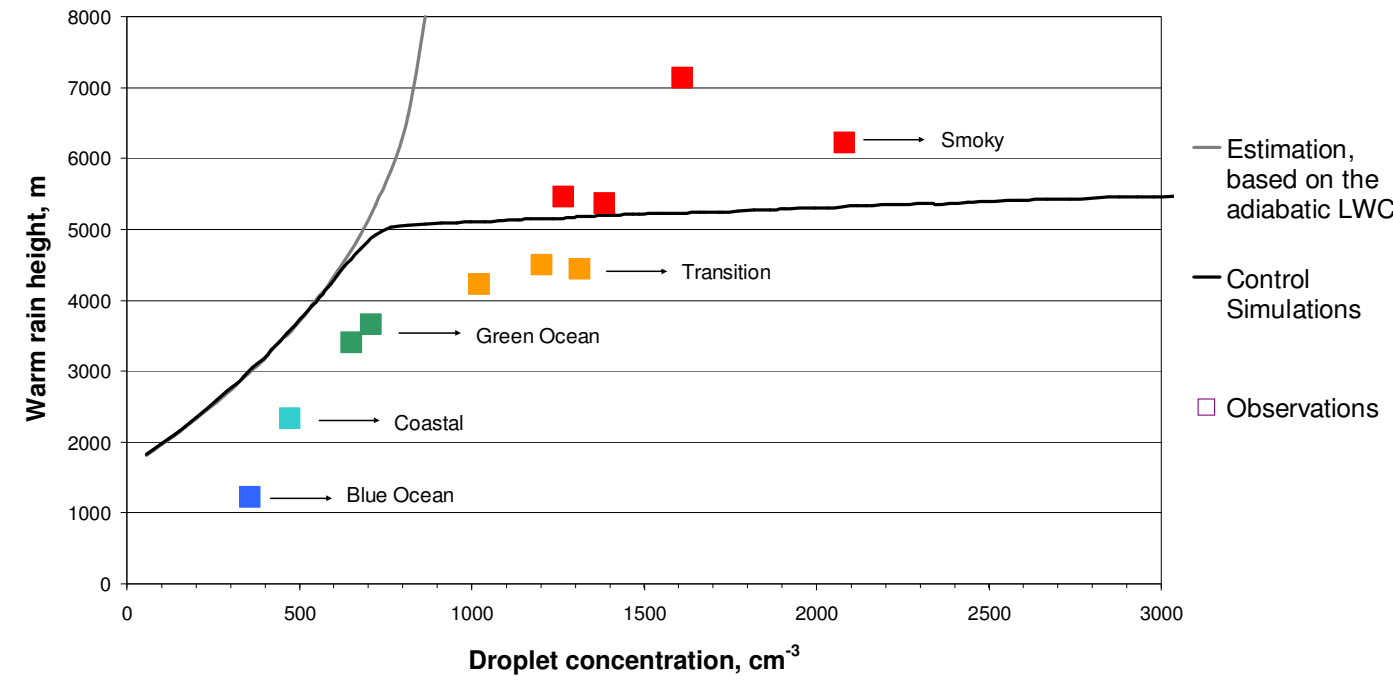

\section{Parcel model simulations of aerosol}

\section{A. A. Costa and}

S. Sherwood

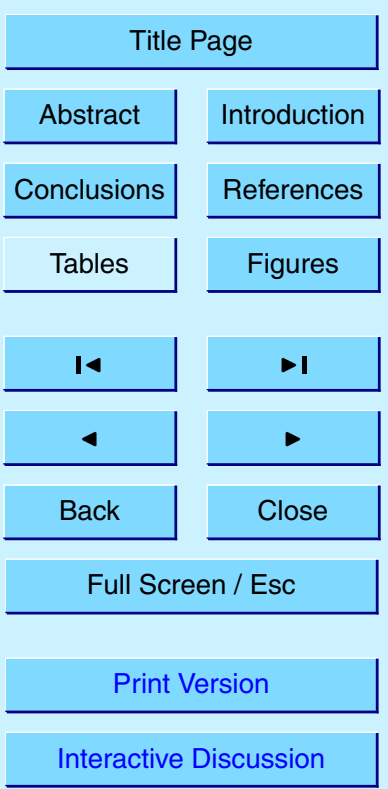

Fig. 3. Observed warm rain height from LBA-SMOCC-EMfiN! observations (symbols), simulated warm rain height values from the parcel model with environmental parameters fixed (dark line), and adiabatic/monomodal estimated warm rain height (pale line), as functions of the droplet concentration. See text for further details. 


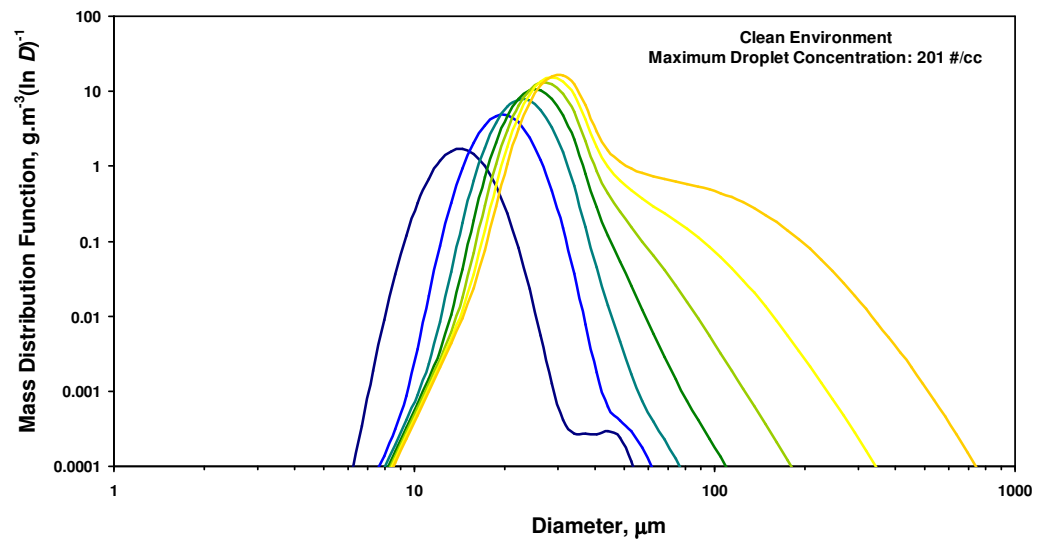

ACPD

$5,481-508,2005$

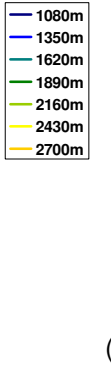

(a)

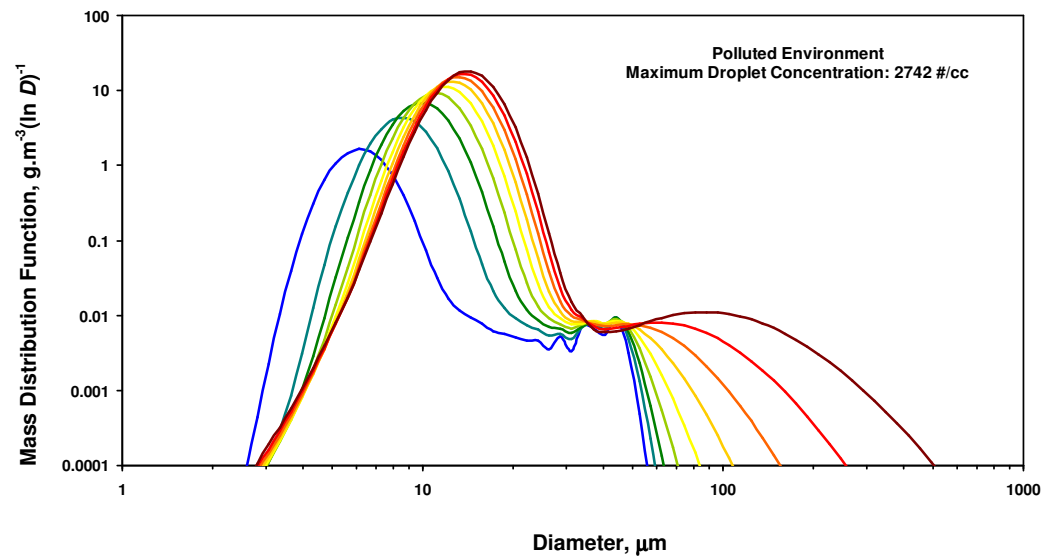

(b)

Fig. 4. Mass distribution-functions for two extreme cases (clean, panel a, versus polluted, panel b) in the control set of simulations. Different curves indicate the time evolution of the droplet spectra (which also corresponds to different heights).

\section{Parcel model simulations of aerosol}

\section{A. A. Costa and}

S. Sherwood

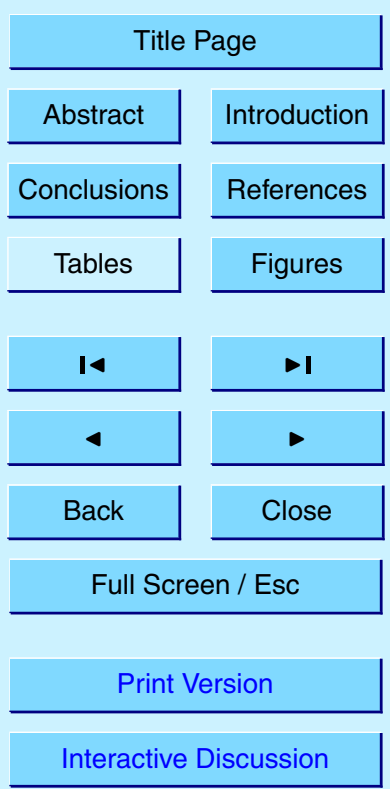

EGU 


\section{ACPD}

$5,481-508,2005$

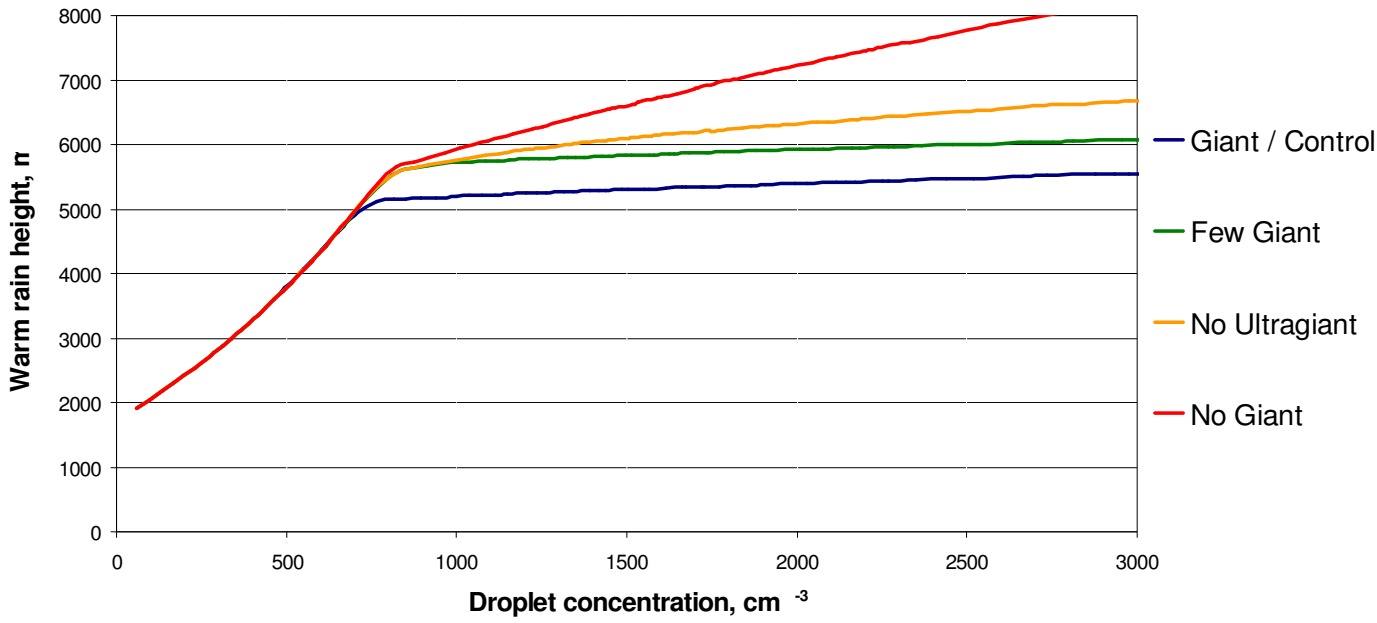

Fig. 5. Simulated warm rain height, as function of the droplet number concentration, for different CCN distributions: control, no UCCN, reduced GCCN/UCCN, and no GCCN/UCCN.

\section{Parcel model simulations of aerosol}

A. A. Costa and

S. Sherwood

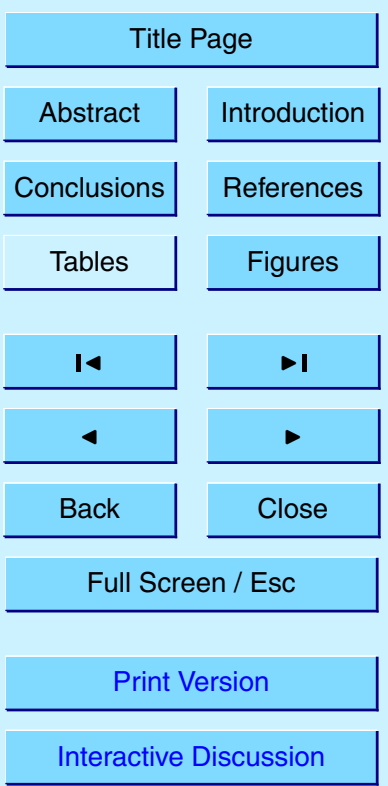




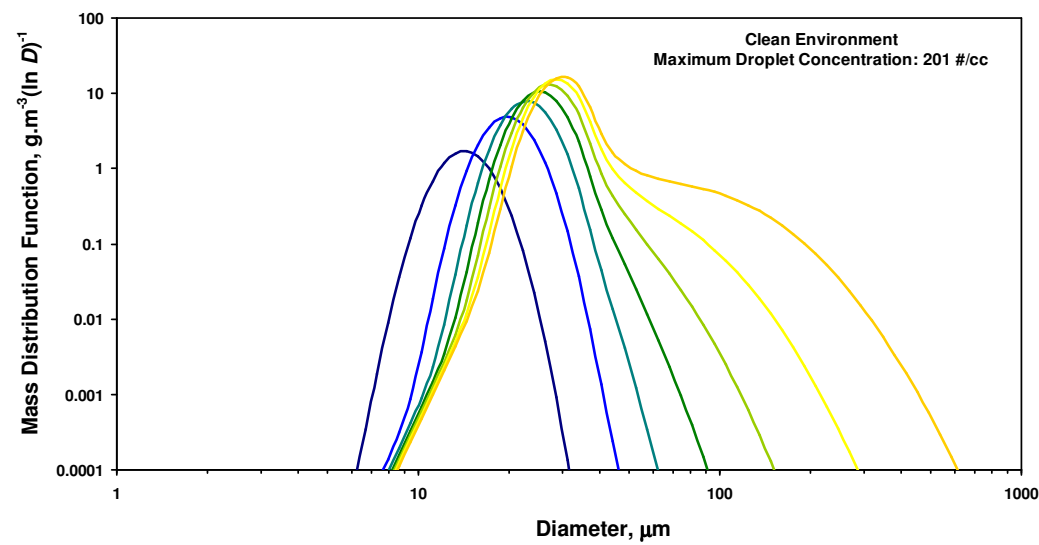

\section{ACPD}

$5,481-508,2005$

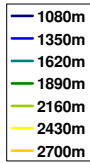

\section{Parcel model simulations of aerosol}

\section{A. A. Costa and}

S. Sherwood

Title Page
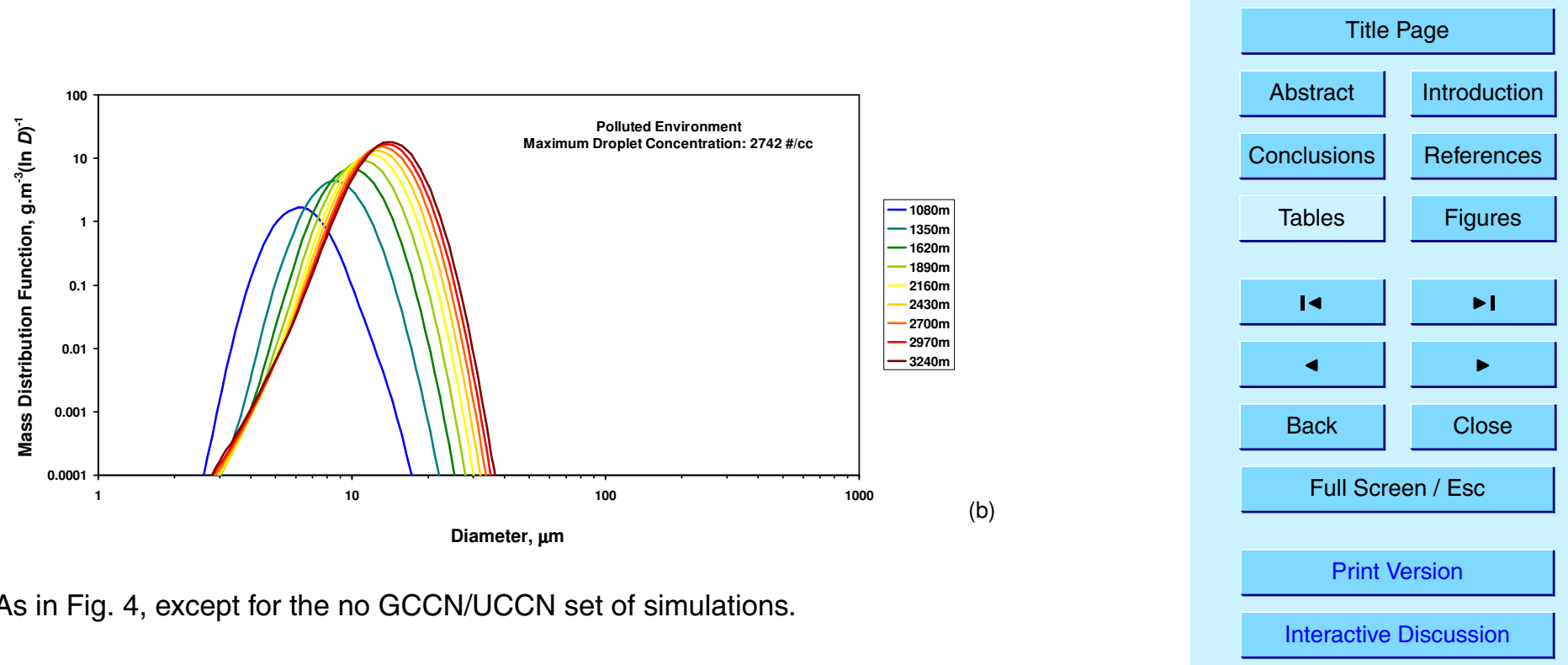

Fig. 6. As in Fig. 4, except for the no GCCN/UCCN set of simulations. 


\section{ACPD}

$5,481-508,2005$

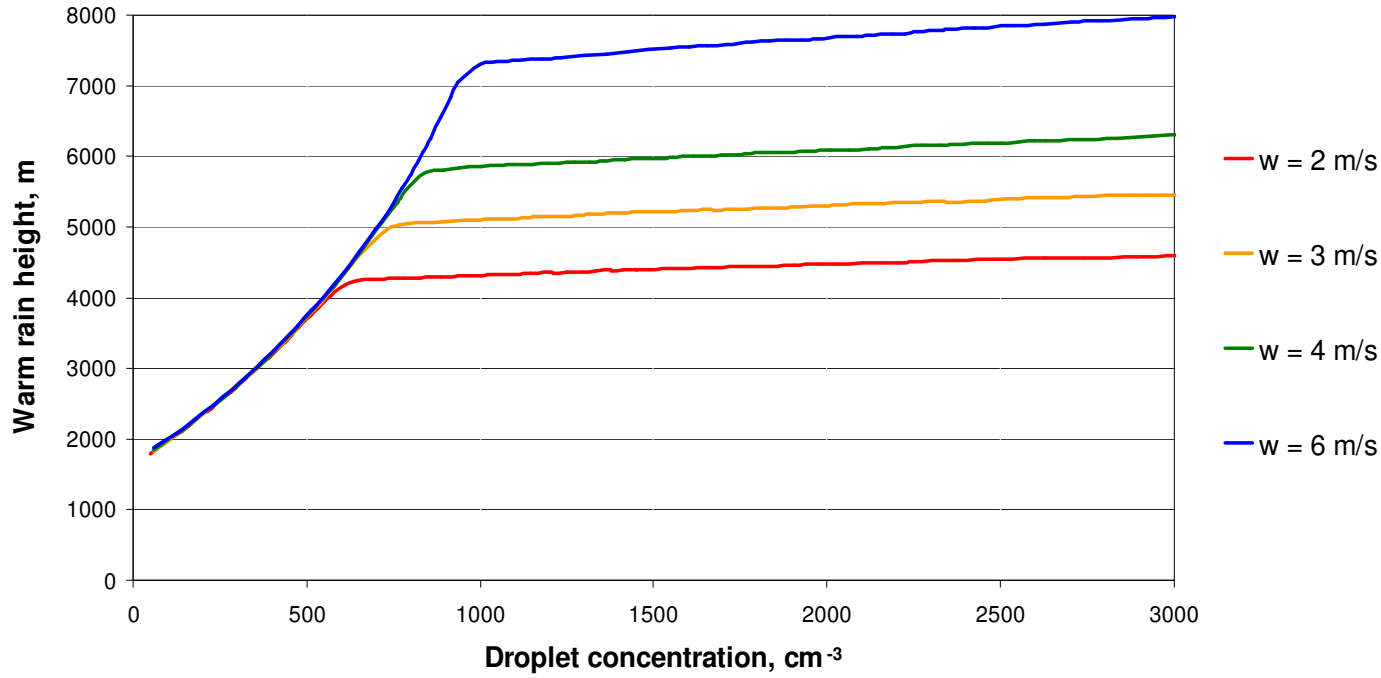

Fig. 7. Same as Fig. 5, except that vertical velocity is varied.

\section{Parcel model simulations of aerosol}

A. A. Costa and

S. Sherwood

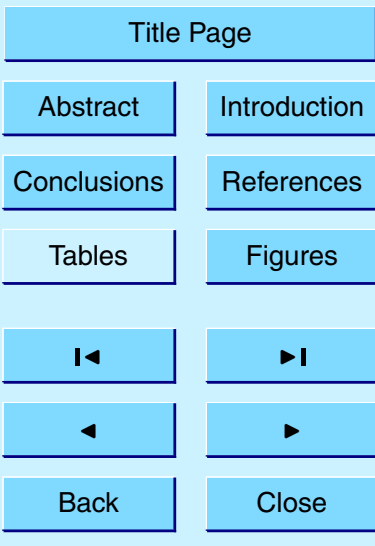

Full Screen / Esc

Print Version

Interactive Discussion 


\section{ACPD}

$5,481-508,2005$

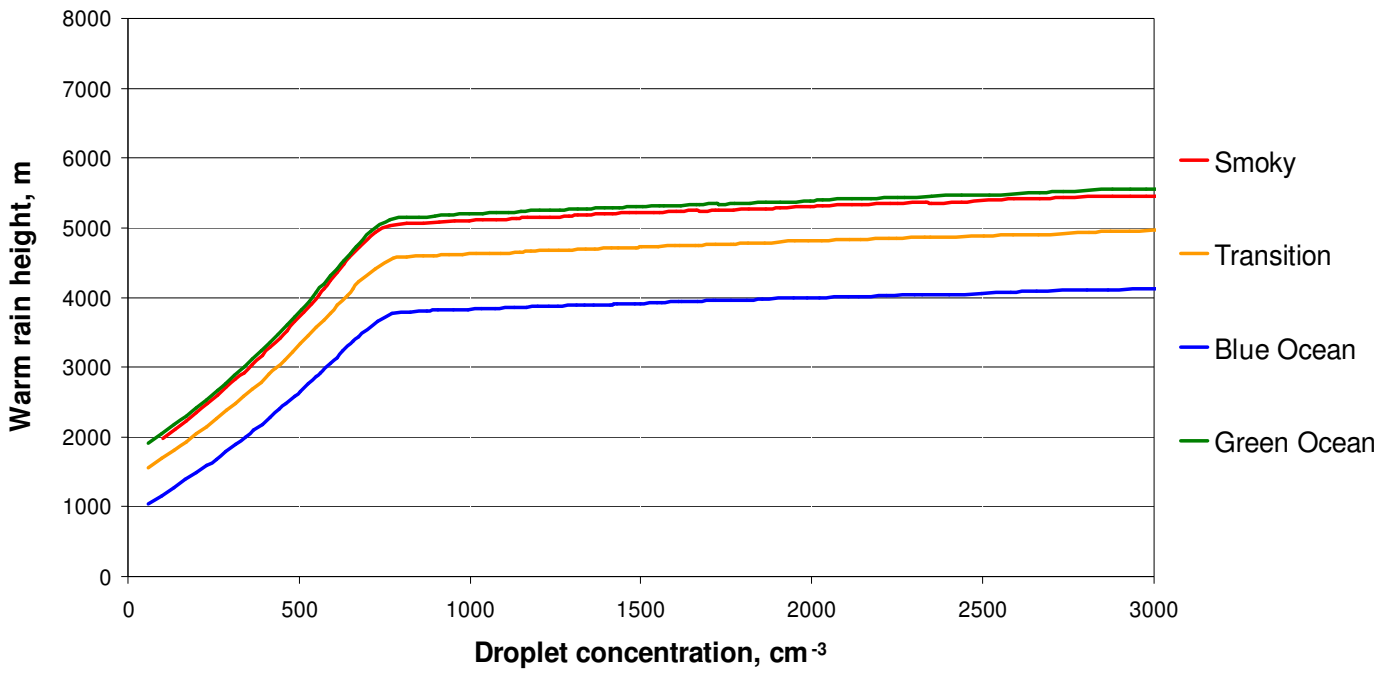

Fig. 8. Same as Fig. 5, except that the different thermodynamic conditions (temperature and water vapor mixing ratio) found in the LBA-SMOCC-EMfiN! campaign (as in Fig. 1) are tried out.

\section{Parcel model simulations of aerosol}

\section{A. A. Costa and}

S. Sherwood

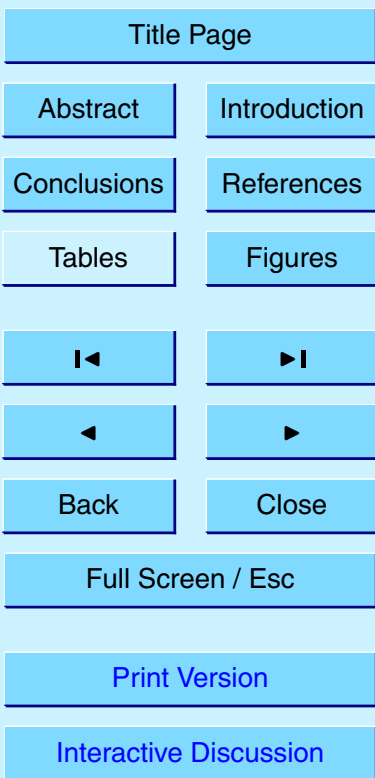




\section{ACPD}

$5,481-508,2005$

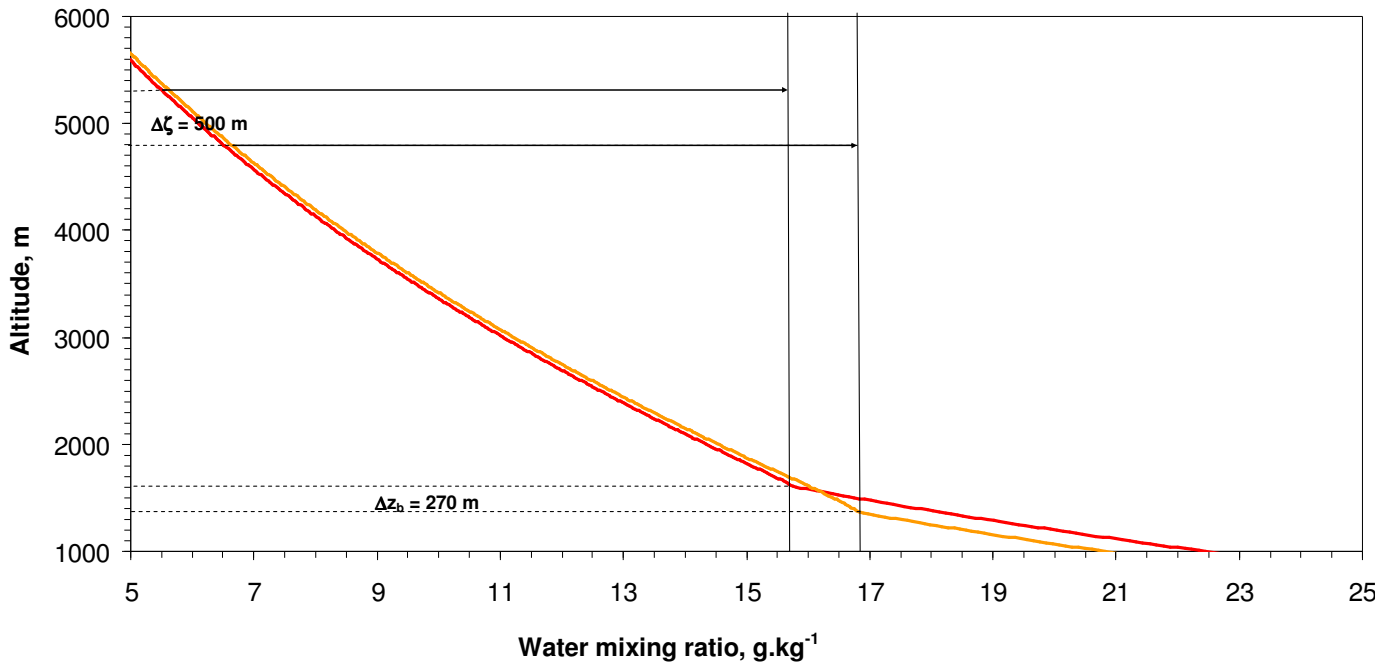

Fig. 9. Vertical profile of the saturation water vapor mixing ratio for the polluted environment (red line) and the transition environment (orange line), as calculated from the parcel model in the control set of simulations. Vertical lines indicate the conserved total water mixing ratio (greater in the transition regime). $\Delta z_{b}$ corresponds to the difference in cloud base heights in the two regimes and $\Delta \zeta$ is the difference in the warm rain heights for clouds with 2000 droplets per cc in each case.

\section{Parcel model simulations of aerosol}

A. A. Costa and

S. Sherwood

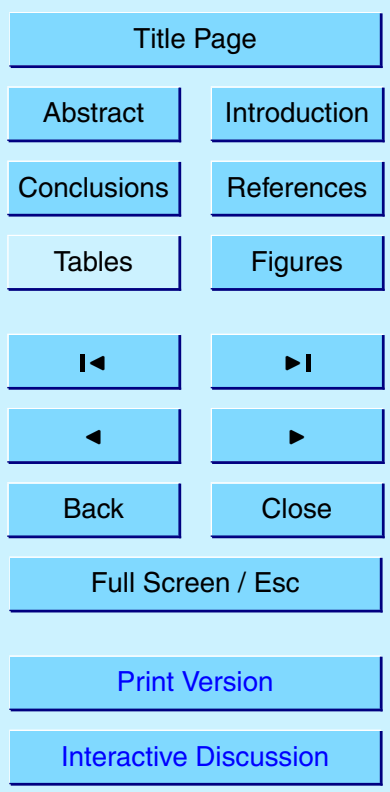




\section{ACPD}

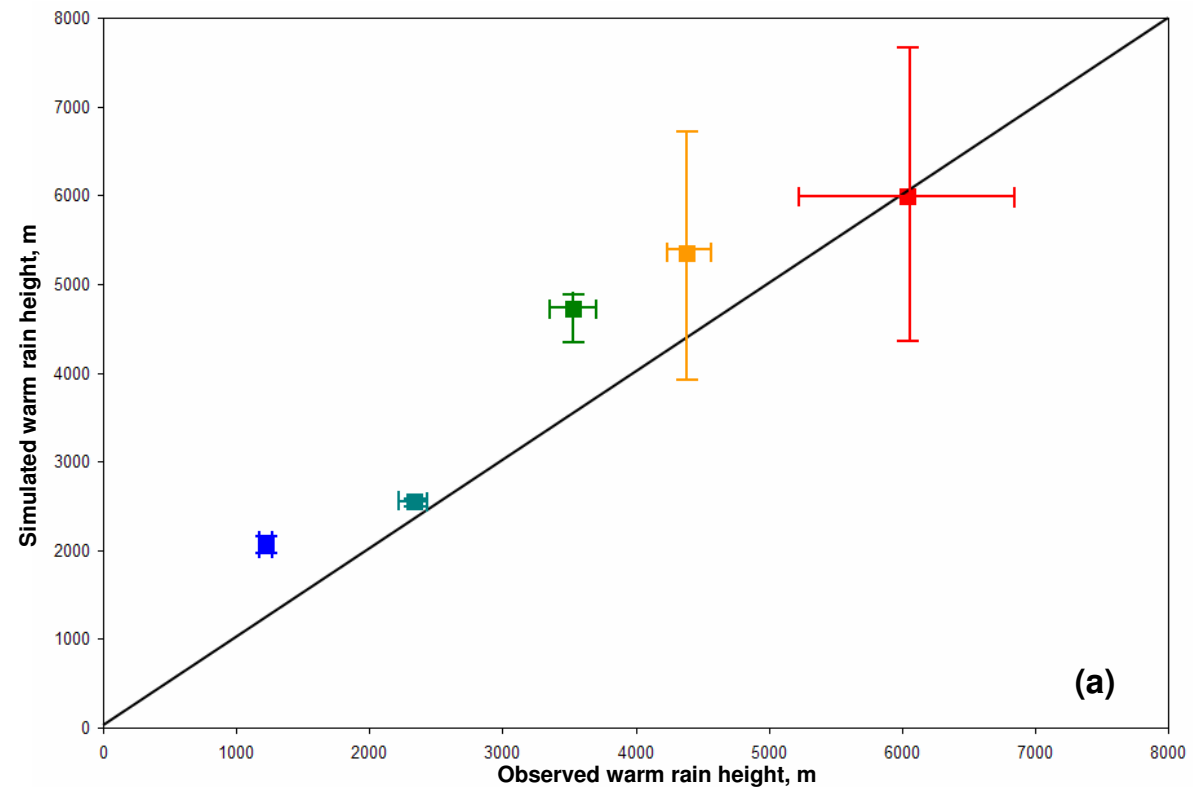

Fig. 10. Simulated versus observed warm rain height with variable environmental parameters; (a) with observed GCCN for each case, (b) no GCCN. Error bars represent results for a likely range of vertical velocity $w(1-4 \mathrm{~m} / \mathrm{s}$ for the blue ocean and coastal clouds, $2-6 \mathrm{~m} / \mathrm{s}$ for the Amazonian clouds). Each square marks the $w$ subjectively chosen to be most representative for each regime, according to LBA-SMOCC-EMfiN! flight logs: $2 \mathrm{~m} / \mathrm{s}$ (blue ocean), $3 \mathrm{~m} / \mathrm{s}$ (coastal), $4 \mathrm{~m} / \mathrm{s}$ (green ocean, transition and smoky regimes). Temperature and humidity for each case taken as in Fig. 1. Uncertainty of observed height is estimated from the sample variances among flights in each regime, assuming that the relative uncertainty $\delta \zeta / \zeta$ is identical for all regimes.
$5,481-508,2005$

\section{Parcel model simulations of aerosol}

A. A. Costa and

S. Sherwood

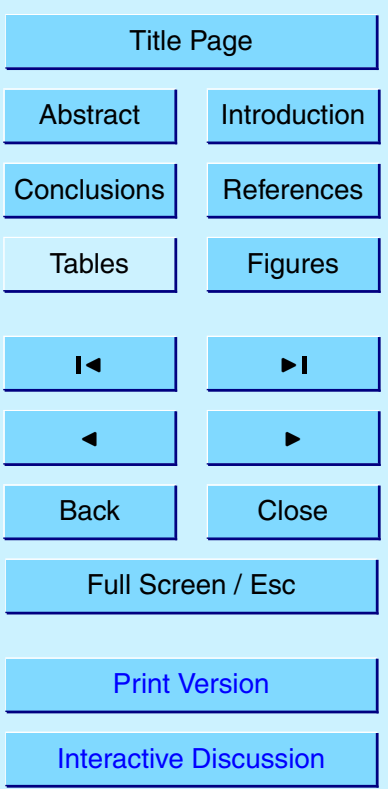




\section{ACPD}

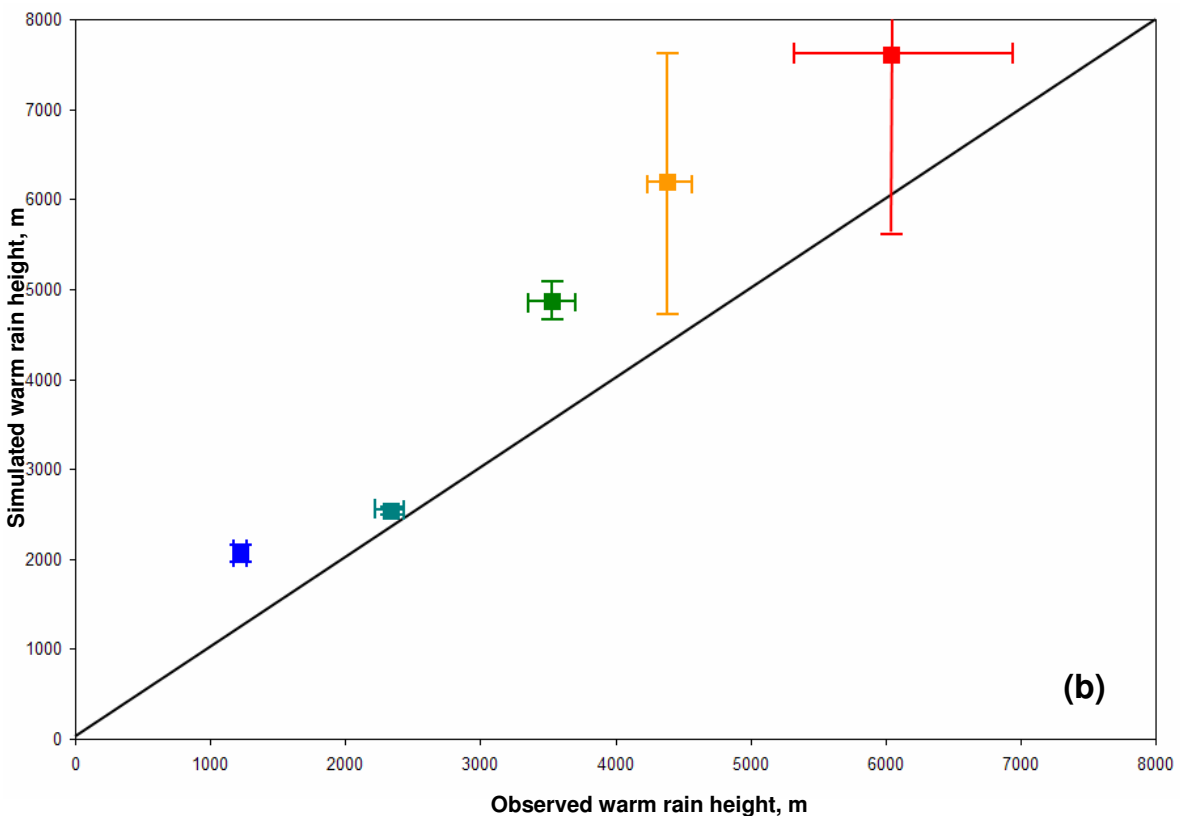

5, 481-508, 2005

\section{Parcel model} simulations of aerosol

A. A. Costa and

S. Sherwood

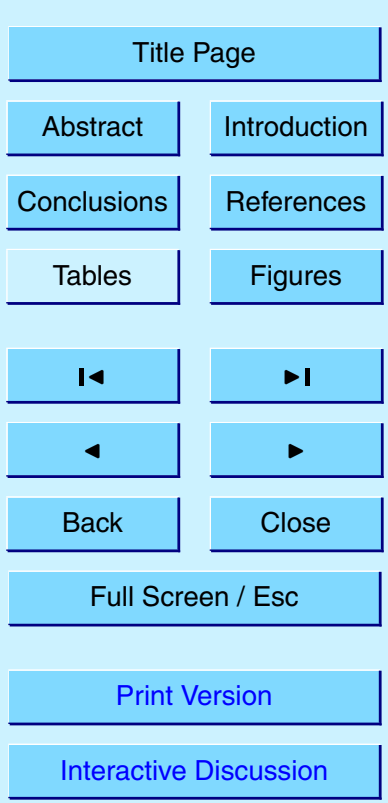

EGU 